\title{
Gambaran Karakteristik Ibu Menyusui Tidak Memberikan ASI Eksklusif di Desa Cikeruh Kecamatan Jatinangor Kabupaten Sumedang Tahun 2015
}

\author{
Silva Agustini Hanifah', Sri Astuti², Ari Indra Susanti \\ ${ }^{1}$ Program Diploma Kebidanan, Fakultas Kedokteran Universitas Padjadjaran \\ ${ }^{2}$ Departemen Ilmu Kesehatan Masyarakat, Fakultas Kedokteran Universitas Padjadjaran
}

\begin{abstract}
Abstrak
Pemberian ASI banyak manfaatnya, baik untuk ibu maupun untuk bayinya, namun kecenderungan untuk ibu menyusui bayinya secara ekslusif masih rendah. Riset WHO pada tahun 2011 di seluruh dunia menyatakan kurang dari 40\% bayi menyusu eksklusif. Rendahnya pemberian ASI ekslusif dapat disebabkan oleh faktor karakteristik, internal, dan eksternal. Penelitian ini bertujuan untuk mengetahui gambaran karakteristik yang dapat menyebabkan ibu tidak memberikan ASI ekslusif di Desa Cikeruh pada bulan Agustus 2015. Metode yang digunakan dalam penelitian ini adalah deskriptif dengan pendekatan potong lintang. Data yang diperoleh adalah data primer yang diperoleh dari kuesioner. Dengan sampel sebanyak 36 orang responden. Analisis statistik yang digunakan adalah univariat. Hasil penelitian ini adalah rendahnya pemberian ASI ekslusif oleh ibu menyusui berdasarkan karakteristik yaitu ibu berusia 20-35 tahun (80,6\%), tidak bekerja $(66,7 \%)$, multipara $(66,7 \%)$, motivasi ibu dalam menyusui $(50 \%)$, ibu dengan pengetahuan kurang $(41,7 \%)$, dukungan keluarga mengenai ASI eksklusif yang rendah $(55,6 \%)$, dan waktu awal pemberian susu formula diberikan kepada bayi saat usia 0-1 bulan $(91,7 \%)$. Simpulan penelitian ini adalah gambaran karakteristik ibu menyusui yang tidak memberikan ASI eksklusif yaitu usia ibu 20-35 tahun, dan waktu ibu memberikan susu formula saat bayi berusia 0-1 bulan.
\end{abstract}

Kata Kunci : ASI eksklusif, Ibu menyusui, Karakteristik

\section{Description of Characteristics Mothers do not Give of Exclusive Breastfeeding in the Village Cikeruh Jatinangor Sumedang 2015}

\begin{abstract}
Breastfeeding has many benefits, both for the mother and for the baby. But, the likelihood of exclusive breastfeeding is still low. Research by WHO in 2011 in all around the world suggested that less than 4\% babies were exclusively breastfed. The low percentage of exclusive breastfeeding might be caused by characteristic, internal, and extenal factors. This study was intended to identify factors that may cause mothers didn't exclusively breastfeed their babies in Cikeruh Village in August 2015. Method used in this study was descriptive with cross sectional approach. Data acquired was primary data through questionnaire. The samples were 36 respondents. Statistic analysis used here was univariat.Result of the study indicated that the characteristic factors that cause the low percentage of exclusive breastfeeding by mother were, the highest one is age range of 20-35 years old $(80.6 \%)$, followed by unemployed mother (66.7\%), and multipara (66.7\%). For the internal factor, mothers' motivation in breastfeeding was 50\%. For external factors, it was caused by the poor knowledge by $41.7 \%$, low family support by $55.6 \%$, and early giving of infant formula to babies with age of 0-1 month (91.7\%).Conclusion from this study is that factors that cause mother do not exclusively breastfeed their babies are mothers' age range of 20-35 years old, and early giving of infant formula to babies with age of 0-1 month.
\end{abstract}

Keywords : Breastfeeding mothers, Characteristics, Exclusive breastfeeding

Korespondensi:

Silva Agustini Hanifah

Program Studi Diploma Kebidanan, Fakultas Kedokteran Universitas Padjadjaran

Jl. Bandung - Sumedang KM. 21 Jatinangor

Mobile : 081809891661

Email : agustinisilva@gmail.com 


\section{Pedahuluan}

Secara umum dipahami bahwa Air Susu Ibu (ASI) adalah gizi terbaik untuk bayi. Khusus untuk bayi yang berumur kurang dari enam bulan dianjurkan agar diberikan ASI eksklusif. Pemberian ASI eksklusif adalah pemberian hanya ASI saja kepada bayi tanpa diberi makan dan minuman lain sejak lahir sampai enam bulan kecuali obat dan vitamin. ASI merupakan makanan bayi yang terbaik dan setiap bayi berhak untuk mendapatkan ASI, maka itu surat keputusan Menteri Kesehatan No.450/MENKES/ SK/IV/2004 tentang pemberian Air Susu Ibu (ASI) secara eksklusif pada bayi di Indonesia. ${ }^{1}$

Sebagian besar ibu menyusui bayinya sejak lahir, namun sebagian besar di antara ibu-ibu tersebut juga memberikan makanan atau minuman selain ASI sejak dini (sebelum bayi berusia enam bulan). ${ }^{2}$ Pemberian MP-ASI yang benar sebaiknya dilakukan setelah bayi berusia enam bulan. Pemberian MP-ASI terlalu dini, yakni kurang dari usia enam bulan, akan memberikan risiko tinggi anak terpapar oleh berbagai macam penyakit. ${ }^{3}$

Air Susu Ibu (ASI) memiliki banyak manfaat, baik untuk ibu maupun bayinya. ASI selalu tersedia dan tidak memerlukan waktu persiapan. Susunya pun segar dan bebas dari kontaminasi bakteri yang akan mengurangi gangguan gastrointestial. Selain itu, pemberian ASI juga dapat meningkatkan daya tahan tubuh. ASI memiliki zat gizi ideal yang komposisinya sesuai dengan kebutuhan bayi dan dapat mencegah penyakit degeneratif. ${ }^{4}$

Meskipun ASI eksklusif sudah diketahui manfaat dan dampaknya, namun kecenderungan untuk ibu menyusui bayinya secara eksklusif masih rendah. Riset WHO pada tahun 2011 di seluruh dunia menyatakan kurang dari $40 \%$ bayi yang berusia kurang dari enam bulan menyusu eksklusif. Berdasarkan Survei Demografi dan Kesehatan Indonesia (SDKI) pada tahun 2012, AKB di Indonesia adalah sebesar 32/1000 kelahiran hidup. Penyebab kematian tersebut erat hubungannya dengan status nutrisi. Kurangnya pemberian ASI eksklusif memberikan kontribusi lebih dari satu juta kematian anak yang dapat dihindari setiap tahunnya. Cakupan ASI eksklusif di Indonesia pada tahun 2007 adalah sebesar $32 \%$, hal ini mengalami kenaikan yang bermakna pada tahun 2012 yaitu sebesar $42 \%{ }^{2}$

Data Riset Kesehatan Dasar (Riskesdas) tahun 2010 di Indonesia menunjukkan bahwa bayi yang mendapatkan ASI eksklusif secara Nasional sebesar 15,3\%. Presentase di perkotaan sebesar $25,2 \%$ dan di pedesaan sebesar $29,3 \%$. Kemudian, laporan Dinas Kesehatan Provinsi pada tahun 2013 menunjukkan bahwa ASI eksklusif di Jawa Barat masih rendah yaitu sebesar
$33,7 \%$, sedangkan target untuk ASI eksklusif pada tahun 2013 adalah 75\%. Maka dari itu, Provinsi Jawa Barat masih belum dapat mencapai target yang diharapkan oleh pemerintah. ${ }^{2}$

Rendahnya pemberian ASI eksklusif oleh ibu menyusui dapat disebabkan oleh faktor karakteristik, internal, dan eksternal. Faktor karakteristik, yaitu umur, pekerjaan dan pendidikan, faktor internal meliputi rendahnya pengetahuan dan sikap ibu, sedangkan faktor eksternal meliputi kurangnya dukungan keluarga, masyarakat, petugas kesehatan maupun pemerintah, gencarnya promosi susu formula, faktor sosial budaya, serta kurangnya ketersediaan fasilitas kesehatan ibu dan anak.

Berdasarkan hasil penelitian yang dilakukan oleh Yuliandarin pada tahun 2009, karakteristik ibu juga menentukan keberhasilan pemberian ASI eksklusif, seperti umur ibu, pekerjaan, dan paritas, yang menjadi faktor yang dapat mendukung keberhasilan pemberian ASI eksklusif. ${ }^{5}$

Usia memengaruhi pengetahuan, motivasi, dan aktivitas seseorang. Usia antara 20-35 tahun merupakan masa reproduksi sehat, karena secara fisik organ reproduksi telah siap, dan kondisi psikologis ibu berdampak terhadap kesiapan dalam menerima kehadiran bayi. Ibu dengan usia yang lebih tua dianggap memiliki pengalaman dalam hal menyusui yang lebih banyak dibandingkan dengan ibu usia muda, sehingga pengetahuannya pun lebih baik dibandingkan dengan ibu usia muda. ${ }^{6}$ Pekerjaan terkadang mempengaruhi keterlambatan ibu untuk memberikan ASI secara eksklusif, secara teknis hal itu dikarenakan kesibukan ibu sehingga tidak cukup untuk memperhatikan kebutuhan ASI. ${ }^{7}$

Paritas ibu merupakan salah satu faktor yang dapat memengaruhi ibu dalam pemberian ASI eksklusif. Berdasarkan hasil penelitian yang dilakukan oleh Ginting, ibu yang memiliki paritas primipara mempunyai risiko lebih besar untuk tidak memberikan ASI eksklusif. Hal ini disebabkan karena ibu yang memiliki paritas multipara telah memiliki pengalaman dalam menyusui dan perawatan bayi. ${ }^{8}$

Pemberian ASI eksklusif paling banyak dijumpai pada ibu berpengetahuan baik. Oleh karena itu, pengetahuan ibu dapat memengaruhi pemberian ASI eksklusif dan dapat memengaruhi motivasi ibu untuk memberikan ASI eksklusif. ${ }^{9}$

Dukungan keluarga berpengaruh terhadap pemberian ASI eksklusif oleh ibu karena dukungan keluarga sangat menguatkan ibu untuk memberikan ASI eksklusif kepada bayinya. ${ }^{10}$ Berdasarkan studi pendahuluan yang dilakukan penulis pada bulan Desember tahun 2014 dengan cara Survei Mawas Diri, sebagian besar ibu meyusui di Desa Cikeruh tidak memberikan ASI 
eksklusif kepada bayinya yaitu sebanyak 55,3\%. Oleh karena itu, penulis tertarik untuk melakukan penelitian mengenai gambaran karakteristik yang terdapat pada ibu menyusui tidak memberikan ASI eksklusif di Desa Cikeruh.

\section{Metode}

Penelitian ini menggunakan metode deskriptif dengan pendekatan cross-sectional. Data yang diambil berupa data primer yang diambil secara langsung kepada responden. Pada penelitian ini pengumpulan data dilakukan hanya pada satu waktu selama penelitian dengan pengambilan sampel menggunakan teknik Total sampling. Penelitian ini dilaksanakan pada bulan Juni sampai dengan bulan Agustus tahun 2015. Penelitian ini dilakukan di Desa Cikeruh Kecamatan Jatinangor, Kabupaten Sumedang. Populasi pada penelitian ini adalah seluruh ibu yang memiliki bayi berusia $0-6$ bulan yang tidak memberikan ASI eksklusif di Desa Cikeruh Kecamatan Jatinangor Kabupaten Sumedang. Besar populasi sebesar 36 orang.

Sampel dalam penelitian ini adalah semua ibu yang memiliki bayi berusia $0-6$ bulan yang tidak memberikan ASI Eksklusif di Desa Cikeruh Kecamatan Jatinangor Kabupaten Sumedang. Kriteria inklusi pada penelitian ini adalah ibu yang tidak mempunyai gangguan psikologis sehingga dapat bekerjasama dalam pelaksanaan penelitian. Sedangkan kriteria eksklusi adalah ibu yang memiliki bayi dengan mengalami kesulitan menghisap akibat kelainan pada rongga mulut atau lahir prematur, ibu yang memiliki penyakit parah yang menghalangi ibu untuk merawat bayi seperti sepsis dan abses payudara.

\section{Hasil}

Tabel 1 Distribusi Frekuensi Berdasarkan Karakteristik Ibu Menyusui yang Tidak Memberikan ASI Eksklusif

\begin{tabular}{lcc}
\hline Karakteristik & Frekuensi (f) & $\begin{array}{c}\text { P e r s e n ta s e } \\
(\%)\end{array}$ \\
\hline Umur & & \\
$<20$ tahun & 2 & 5,6 \\
$20-35$ tahun & 29 & 80,6 \\
$\quad>35$ tahun & 5 & 13,9 \\
Pekerjaan & & \\
$\quad$ Bekerja & 12 & 33,3 \\
Tidak bekerja & 24 & 66,7
\end{tabular}

\begin{tabular}{lcc} 
Paritas & & \\
Primipara & 11 & 30,6 \\
Multipara & 24 & 66,7 \\
Grandemultipara & 1 & 2,8 \\
\hline
\end{tabular}

Berdasarkan tabel di atas, tampak bahwa responden terbanyak berusia 20-35 tahun $(80,6 \%)$, ibu menyusui yang menjadi responden dalam penelitian ini yang tidak bekerja $(66,7 \%)$ dan kategori paritas yaitu multipara $(66,7 \%)$.

Tabel 2 Distribusi Frekuensi Berdasarkan Motivasi Ibu Menyusui yang Tidak Memberikan ASI Eksklusif

\begin{tabular}{ccc}
\hline Motivasi & Frekuensi (f) & Persentase (\%) \\
\hline Tinggi & 18 & 50,0 \\
Rendah & 18 & 50,0 \\
Total & $\mathbf{3 6}$ & $\mathbf{1 0 0}$ \\
\hline
\end{tabular}

Berdasarkan tabel 2 tampak bahwa responden yang memiliki motivasi tinggi dan rendah masing-masing sebesar $(50,0 \%)$.

Tabel 3 Distribusi Frekuensi Berdasarkan Pengetahuan Ibu Menyusui yang Tidak Memberikan ASI Eksklusif

\begin{tabular}{ccc}
\hline Pengetahuan & Frekuensi (f) & Persentase (\%) \\
\hline Baik & 7 & 19,4 \\
Cukup & 14 & 38,9 \\
Kurang & 15 & 41,7 \\
Total & $\mathbf{3 6}$ & $\mathbf{1 0 0}$ \\
\hline
\end{tabular}

Dari tabel di atas, tampak bahwa responden yang memiliki pengetahuan baik (19,4\%), pengetahuan cukup $(38,9 \%)$ dan pengetahuan kurang $(41,7 \%)$. Dari tabel tersebut, yang terbanyak adalah ibu menyusui yang tidak memberikan ASI eksklusif yang memiliki pengetahuan kurang.

Tabel 4 Distribusi Frekuensi Berdasarkan Dukungan Keluarga Ibu Menyusui yang Tidak Memberikan ASI Eksklusif

\begin{tabular}{ccc}
\hline $\begin{array}{c}\text { Dukungan } \\
\text { Keluarga }\end{array}$ & Frekuensi (f) & Persentase (\%) \\
\hline Tinggi & 16 & 44,4 \\
Rendah & 20 & 55,6 \\
Total & $\mathbf{3 6}$ & $\mathbf{1 0 0}$ \\
\hline
\end{tabular}

Berdasarkan tabel 4, tampak bahwa responden yang memiliki dukungan keluarga tinggi $(44,4 \%)$, sedangkan dukungan keluarga rendah $(55,6 \%)$. Dari tabel tersebut, yang terbanyak adalah ibu 
menyusui yang tidak memberikan ASI eksklusif yang memiliki dukungan keluarga yang rendah.

$\begin{array}{lcc}\text { Tabel 5 Distribusi } & \text { Frekuensi } & \text { Berdasarkan } \\ \text { Waktu Awal Pemberian Susu Formula Oleh } \\ \text { Ibu Menyusui yang Tidak Memberikan ASI } \\ \text { Eksklusif }\end{array}$

Berdasarkan tabel di atas, tampak bahwa waktu awal pemberian susu formula pada usia $0-1$ bulan $(91,7 \%)$, sedangkan $2-4$ bulan $(8,3 \%)$. Dari tabel tersebut, waktu awal pemberian susu formula cenderung pada usia $0-1$ bulan

\section{Pembahasan}

Karakteristik menentukan keberhasilan pemberian ASI eksklusif, umur ibu, pekerjaan, dan paritas menjadi tiga faktor strategis yang mendukung keberhasilan pemberian ASI eksklusif.9 Berdasarkan hasil penelitian bahwa ibu menyusui yang tidak memberikan ASI eksklusif di Desa Cikeruh terbanyak adalah yang berusia 20-35 tahun $(80,6 \%)$, hal tersebut tidak sesuai dengan peneliatan yang menyebutkan bahwa proporsi pemberian ASI eksklusif lebih banyak diberikan oleh ibu berusia muda daripada ibu berusia tua. ${ }^{5}$ usia 20-35 tahun merupakan usia yang baik untuk masa reproduksi, dan pada umumnya pada usia tersebut memiliki kemampuan laktasi yang lebih baik dibandingkan dengan ibu yang usianya lebih dari 35 tahun sebab pengeluaran ASI-nya lebih sedikit dibandingkan dengan yang berusia reproduktif. Sedangkan pada usia kurang dari 20 tahun secara psikis umumnya belum siap untuk menjadi ibu, sehingga bisa menjadi beban psikologis yang akan menyebabkan depresi dan menyebabkan ASI susah untuk keluar. Pada penelitian ini ibu yang berusia reproduktif tersebut tidak memberikan ASI eksklusif karena motivasi ibu yang rendah. Berdasarkan pekerjaan terbanyak tidak bekerja $(66,7 \%)$, hal ini tidak sesuai dengan penelitian yang menyebutkan bahwa ibu yang tidak bekerja berpeluang memberikan ASI eksklusif 16,4 kali lipat ibu yang bekerja, ${ }^{5}$ Status pekerjaan ibu merupakan faktor yang bersifat memproteksi, artinya ibu yang tidak berkerja akan lebih mendukung dalam pemberian ASI eksklusif dibandingkan dengan ibu yang bekerja. Hal ini dikarenakan ibu yang melakukan pekerjaan di rumah akan memiliki banyak waktu dan kesempatan untuk menyusui bayinya, dibandingkan dengan ibu yang bekerja di luar rumah. ${ }^{11}$ Dalam penelitian ini ibu yang tidak bekerja tidak memberikan ASI eksklusif disebabkan oleh berbagai hal, seperti pengetahuan, air susu ibu yang keluar hanya sedikit dan karena faktor dari dukungan keluarga. Berdasarkan paritas terbanyak multipara $(66,7 \%)$, bagi ibu dengan paritas multipara pengalaman menyusui memang berperan penting bagi ibu untuk menyusui kembali sehingga meneruskan dari pengalaman anak sebelumnya. Namun semuanya tergantung pada pengalaman ibu sendiri untuk memberikan ASI-nya dengan banyak bertanya kepada petugas kesehatan atau dengan motivasi ibu untuk menyusui bayinya yang tinggi.

Berdasarkan hasil penelitian yang telah dilakukan di Desa Cikeruh, ibu yang tidak memberikan ASI eksklusif pada responden ini mempunyai motivasi tinggi dan rendah yang sama besar yaitu sebesar 50\%. Berdasarkan hasil kuesioner didapatkan bahwa motivasi ibu yang tinggi salah satunya disebabkan ibu tidak mudah terpengaruh oleh informasi elektronik seperti iklan susu formula, dan ibu mempunyai motivasi untuk tetap memberikan ASI eksklusif. Sumber informasi yang tepat mengenai ASI eksklusif oleh petugas kesehatan yang diberikan kepada siapa saja sedini mungkin agar terjadi lingkungan yang mendukung ibu terhadap pemberian ASI eksklusif. Sedangkan motivasi ibu yang rendah salah satunya disebabkan pada saat itu ASI ibu belum keluar dan masih sedikit serta bayi terus menerus menangis sehingga ibu memberikan susu formula kepada bayi. Padahal, menurut teori, bayi aterm yang tumbuh sehat lahir dengan cadangan glikogen yang baik dan kadar hormon antidiuretik yang tinggi. Akibatnya, bayi tidak membutuhkan volume susu atau kolostrum dalam jumlah yang besar segera setelah lahir karena kebutuhan tersebut telah tersedia secara fisiologis. Mengenai bayi yang terus menerus menangis sehingga ibu memberikan susu formula, mungkin disebabkan karena ibu kurang memahami kondisi psikologis bayi bahwa tangisan bayi itu berbeda-beda dan dapat menandakan perbedaan kebutuhan. ${ }^{12}$

Dari hasil penelitian mengenai pengetahuan ibu menyusui yang tidak memberikan ASI eksklusif di Desa Cikeruh memiliki pengetahuan yang baik sebesar 19,4\%, pengetahuan cukup sebesar 38,9\% dan ibu yang bepengetahuan kurang sebesar $41,7 \%$. Dengan demikian, ibu menyusui yang tidak memberikan ASI eksklusif cenderung memiliki pengetahuan yang kurang. 
Dari hasil penelitian yang diperoleh dari pengisian kuesioner, didapatkan bahwa rendahnya pengetahuan ibu dikarenakan ibu kurang memahami cara penyimpanan ASI di dalam suhu ruangan dan cara pemberian ASI kepada bayi. Menurut teori, cara penyimpanan ASI di dalam suhu ruangan dapat bertahan sampai enam jam, dan cara pemberian ASI yang telah dikeluarkan dengan cara pemberiannya pada bayi yang baik perlu diperhatikan. Sebaiknya pemberian ASI yang telah dikeluarkan bukan diberikan dengan botol/dot, karena hal ini akan menyebabkan bayi "bingung puting", melainkan diberikan dengan menggunakan cangkir atau sendok, sehingga bila saatnya ibu menyusui langsung, bayi tidak menolak untuk menyusu.

Pemberian dengan menggunakan sendok biasanya kurang praktis dibandingkan dengan cangkir karena membutuhkan waktu yang lebih lama. Namun pada keadaan bayi yang membutuhkan hanya sedikit ASI, atau bayi sering tersedak/muntah, maka lebih baik bila ASI perasan diberikan dengan menggunakan sendok. ${ }^{13}$

Pengetahuan merupakan domain yang sangat penting untuk terbentuknya perilaku seseorang. Pengetahuan merupakan pengindraan manusia, atau hasil tahu seseorang terhadap objek melalui indera yang dimilikinya. ${ }^{14}$ Pengetahuan seseorang dapat dipengaruhi oleh beberapa faktor seperti, pengalaman, keyakinan, fasilitas, penghasilan dan sosial budaya. Adanya fasilitas seperti media cetak atau elektronik dapat meningkatkan pengetahuan seseorang, terutama ibu menyusui dalam mendapatkan pengetahuan mengenai ASI eksklusif melalui fasilitas seperti kelompok pendukung ASI dan media seperti selebaran (leaflet) sehingga ibu menyusui dapat mengetahui informasi tentang ASI eksklusif.

Berdasarkan hasil penelitian mengenai dukungan keluarga ibu menyusui yang tidak memberikn ASI eksklusif yaitu ibu yang memiliki dukungan keluarga tinggi sebanyak 44,4\%, sedangkan ibu dengan dukungan keluarga yang rendah 55,6\%. Dengan demikian, ibu menyusui yang tidak memberikan ASI eksklusif cenderung memiliki dukungan keluarga yang rendah.

Dari hasil penelitian yang diperoleh dari pengisian kuesioner, didapatkan bahwa rendahnya dukungan keluarga disebabkan karena keluarga cenderung menganjurkan ibu untuk merawat bayi dan melakukan pekerjaan rumah sendiri. Hal tersebut sesuai dengan penilitian yang dilakukan Dykes di Nort West of England yang menyatakan bahwa dukungan keluarga berpengaruh positif terhadap pemberian ASI eksklusif. ${ }^{10}$ Dukungan keluarga merupakan salah satu unsur penting dalam menyukseskan ASI eksklusif. Dukungan keluarga akan meningkatkan kepercayaan diri dan menumbuhkan motivasi. Interaksi positif dengan keluarga akan menimbulkan kasih sayang dan dukungan moril. Bentuk dukungan keluarga dapat berupa dukungan emosional, materi dan informasi. Maksud dari dukungan emosional keluarga adalah menjadi sebuah tempat yang aman dan damai untuk istirahat dan pemulihan serta membantu penguasaan terhadap emosi, meliputi ungkapan empati, kepedulian dan perhatian terhadap anggota keluarga yang mengalami suatu permasalahan atau membutuhan bantuan. Dalam penelitian ini, ibu menyusui membutuhkan keluarga untuk dapat membantu ibu dalam merawat bayi dan membantu ibu dalam pekerjaan rumah, sehingga ibu dapat merasa mendapatkan dukungan dari keluarganya untuk dapat menyusui bayinya.

Berdasarkan hasil penelitian mengenai waktu awal pemberian susu formula oleh ibu menyusui yang tidak memberikan ASI eksklusif di Desa Cikeruh pada saat bayi berusia 0-1 bulan adalah sebanyak $91,7 \%$, dan pada saat bayi berusia 2-4 bulan adalah sebanyak $8,3 \%$. Dari hasil penelitian tersebut, ibu yang memberikan susu formula pada saat bayi berusia 0-1 bulan disebabkan oleh beberapa alasan seperti air susu ibu yang belum keluar atau air susu ibu yang keluar hanya sedikit, dan karena faktor pekerjaan, karena saat ibu bekerja di luar rumah, anak dititipkan kepada saudara atau nenek ataupun pembantu. Dengan demikian, saat ibu bekerja anak sangat bergantung pada siapapun tokoh yang menggantikan ibu ketika meninggalkan rumah. Setelah pulang bekerja, kondisi fisik dan mental yang lelah setelah bekerja sepanjang hari menghambat kelancaran memproduksi ASI, hal tersebut mengurungkan niat ibu bekerja untuk memberikan ASI eksklusif. ${ }^{11}$

Bayi siap untuk menerima makanan atau cairan selain ASI baik secara pertumbuhan maupun secara psikologis pada usia 6-9 bulan. Kemampuan bayi mencerna, mengabsorpsi, dan memetabolisme bahan makanan sudah adekuat, tetapi terbatas hanya beberapa fungsi. World Health Organization merekomendasikan empat hal penting yang harus dilakukan untuk mencapai tumbuh kembang optimal yaitu pertama memberikan air susu ibu kepada bayi segera dalam waktu 30 menit setelah bayi lahir, kedua memberikan hanya air susu ibu (ASI) saja kepada bayi atau pemberian ASI secara eksklusif sejak lahir sampai usia 6 bulan, ketiga memberikan makanan atau minuman endamping ASI sejak bayi berusia 6 bulan sampai 24 bulan dan keempat meneruskan pemberian ASI sampai anak berusia 24 bulan. Pemberian makanan atau minuman pendamping ASI yang tidak sesuai dengan umur dan kebutuhan bayi dapat menimbukan dampak 
pada kesehatan dan status gizi bayi. Pada beberapa penelitian pemberian makanan atau minuman selain ASI secara dini seperti pemberian susu formula, akan menunjukan status gizi bayi yang kurang, hal tersebut akan berdampak terhadap kesehatan bayi diantaranya adalah gangguan pencernaan seperti diare, sulit BAB, muntah, serta bayi akan mengalami gangguan menyusui. ${ }^{15}$

Simpulan pada penelitian ini Berdasarkan hasil penelitian yang telah dilakukan mengenai Gambaran karakteristik Ibu Menyusui Tidak Memberikan ASI Eksklusif di Desa Cikeruh Kecamatan Jatinangor, maka dapat disimpulkan sebagai berikut, gambaran karakteristik ibu menyusui yang tidak memberikan ASI eksklusif yang terbanyak adalah yang berusia 20-35 tahun $(80,6 \%)$, berdasarkan pekerjaan yang terbanyak adalahyangtidakbekerja $(66,7 \%)$, dan berdasarkan paritas yang terbanyak adalah multipara $(66,7 \%)$.

Gambaran motivasi ibu menyusui yang tidak memberikan ASI eksklusif yang mempunyai motivasi tinggi dan rendah masing-masing sebesar 50\%. Gambaran pengetahuan ibu menyusui yang tidak memberikan ASI eksklusif didapatkan 19,4\% ibu memiliki pengetahuan baik, 38,9\% ibu memiliki pengetahuan cukup dan $41,7 \%$ ibu memiliki pengetahuan kurang. Gambaran dukungan keluarga ibu menyusui yang tidak memberikan ASI eksklusif yang terbanyak adalah yang memiliki dukungan keluarga yang rendah yaitu sebesar 55,6\%. Gambaran waktu awal pemberian susu formula oleh ibu menyusui yang tidak memberikan ASI eksklusif yaitu pada saat bayi berusia $0-1$ bulan $(91,7 \%)$.

Saran untuk penelitian ini adalah Bidan dapat memberikan pengetahuan dan memotivasi ibu dalam pemberian ASI eksklusif baik pada saat ibu hamil ataupun setelah melahirkan dengan memanfaatkan beberapa program seperti kelas ibu hamil, menerapkan inisiasi menyusu dini setelah ibu bersalin, atau pengadaan kelompok pendukung ASI. Bidan pun dapat bekerja sama dengan kader sehingga para kader dapat memberikan informasi kepada ibu menyusui yang ada di Desa Cikeruh, serta kader mampu mendampingi bidan dalam memberikan informasi dan motivasi kepada ibu tentang pemberian ASI eksklusif, misalnya pada saat posyandu dengan memberikan informasi melalui media selebaran (leaflet).

\section{Daftar Pustaka}

1. Departemen Kesehatan Indonesia dan Kementrian Kesehatan Republik Indonesia. 2004.

2. Pusat data dan informasi kementrian kesehatan RI. Jakarta. 2013.

3. Kurniasih D, H.H., Astuti MP, Imam S, sehat dan bugar berkat gizi seimbang. jakarta: gramedia. 2010.

4. Arvin, b.k., Nelson ilmu kesehatan anak. Vol. 1. EGC. 2000.

5. Yuliandarin, faktor-faktor yang memengaruhi ASI eksklusif. p. 2009.

6. Inayati. Beberapa Faktor Yang Berhubungan Dengan Pengetahuan Menyusui, Menyusui Eksklusif Dan Manajemen Laktasi Pada Petugas Kesehatan Di Rsu Bakti Ushada Depok. Jakarta: Skripsi FKM UI. 2007.

7. IDAI. Indonesia menyusui. Jakarta: badan penerbit IDAI. 2010.

8. Hidajati.A. mengapa seorang ibu harus menyusui?. Jakarta: flashbook. 2012.

9. Husna, A., pengaruh karakteristik, pengetahuan dan sikap ibu terhadap pemberian ASI eksklusif. medan: FKM. 2008.

10. Simbolon, f., pengaruh dukungan keluarga terhadap pemberian ASI eksklusif. medan: FKM. 2011.

11. Djuwita, a., pola pemberian susu formula dan konsumsi zat gizi anak usia dua tahun pada ibu bekerja dan tidak bekerja. bogor: FEMA IPB. 2006.

12. Soetjiningsih, ASI petunjuk untuk tenaga kesehatan. jakarta: EGC. 2007.

13. Fraser, Diane M. dan Margaret A. Cooper. Myles textbook for midwives. 15th Edition. London: churchill livingstone Elsevier.2009.

14. Notoatmojo, Soekidjo. Metodelogi Penelitian Kesehatan. Jakarta: Rineka Cipta: 2010.

15. Wargiana R, hubungan pembeiran MP-ASI dini dengan status gizi bayi umur 0-6 bulan. Jurnal pustaka kesehatan. Vo 1. 2013. 